\title{
BMJ Open The effect of ketorolac on posterior thoracolumbar spinal fusions: a prospective double-blinded randomised placebo-controlled trial protocol
}

Chad F Claus, ${ }^{1}$ Evan Lytle, ${ }^{1}$ Doris Tong, ${ }^{1}$ Diana Sigler, ${ }^{2}$ Dominick Lago, ${ }^{3}$
Matthew Bahoura, ${ }^{1}$ Amarpal Dosanjh, ${ }^{1}$ Michael Lawless, ${ }^{1}$ Dejan Slavnic, ${ }^{1}$
Prashant Kelkar, ${ }^{1}$ Clifford Houseman, ${ }^{1}$ Peter Bono, ${ }^{1}$ Boyd Richards, ${ }^{1}$ Teck M Soo ${ }^{1}$

To cite: Claus CF, Lytle E, Tong D, et al. The effect of ketorolac on posterior thoracolumbar spinal fusions: a prospective double-blinded randomised placebo-controlled trial protocol. BMJ Open 2019;9:e025855. doi:10.1136/ bmjopen-2018-025855

- Prepublication history for this paper is available online. To view these files, please visit the journal online (http://dx.doi org/10.1136/bmjopen-2018025855).

Received 5 August 2018 Revised 19 November 2018 Accepted 3 December 2018

Check for updates

(C) Author(s) (or their employer(s)) 2019. Re-use permitted under CC BY-NC. No commercial re-use. See rights and permissions. Published by BMJ.

${ }^{1}$ Division of Neurosurgery, Department of Surgery,

Ascension Providence Hospital, Michigan State University, College of Human Medicine, Southfield, Michigan, USA ${ }^{2}$ Department of Pharmacy, Ascension Providence Hospital, Southfield, Michigan, USA ${ }^{3}$ Division of Neuro-anesthesia, Department of Anesthesia, Ascension Providence Hospital, Michigan State University, College of Human Medicine, Southfield, Michigan, USA

Correspondence to

Dr Chad F Claus;

chadfclaus@gmail.com

\section{ABSTRACT}

Introduction Ketorolac has been shown to provide quality postoperative pain control and decrease opioid requirement with minimal side effects following spinal surgery. However, the literature addressing its use in spinal fusions is highly variable in both its effectiveness and complications, such as pseudarthrosis. Recent literature postulates that ketorolac may not affect fusion rates and large randomised controlled trials are needed to demonstrate ketorolac as a safe and effective adjuvant treatment to opioids for postoperative pain control.

Methods and analysis This is a multihospital, prospective, double-blinded, randomised placebocontrolled trial. Data concerning fusion rates, postoperative opioid use, pain scores, length of stay will be recorded with the aim of demonstrating that the use of ketorolac does not decrease thoracolumbar spinal fusion rates while identifying possible adverse events related to shortterm minimal effective dose compared with placebo. Additionally, this investigation aims to demonstrate a decrease in postoperative opioid use demonstrated by a decrease in morphine equivalence while showing equivalent postoperative pain control and decrease the average length of stay.

Ethics and dissemination Ethical approval was obtained at all participating hospitals by the institutional review board. The results of this study will be submitted for publication in peer-reviewed journals. Trial registration number NCT03278691.

\section{INTRODUCTION}

Spinal fusion surgeries are one of the most common spinal procedures performed for the treatment of degenerative, traumatic, congenital and neoplastic spine conditions. ${ }^{1} \quad$ Non-steroidal anti-inflammatory drugs (NSAIDs), more specifically, ketorolac have been used as an effective analgesic for postoperative pain control, in addition to a well-described opioid-sparing effect. $^{2-6}$ Despite their analgesic success, the use of NSAIDs in spine surgeries is limited, as past studies have demonstrated inhibitory effects

\section{Strengths and limitations of this study}

- First randomised controlled trial to evaluate the effect of ketorolac on thoracolumbar spinal fusions.

- Adequately powered study to provide a clinically meaningful result.

on fracture healing ${ }^{7-14}$ with more recent reports describing similar effects on spinal fusions. ${ }^{15-23}$ Pseudarthrosis or non-union is a known complication following spinal fusions with a reported rate $3-35 \% .{ }^{24-27}$ Many factors contribute to pseudarthrosis, including smoking, body mass index (BMI) or NSAID use. ${ }^{28}{ }^{29}$ NSAIDs were and have been historically avoided for postoperative spine patients because of the possible deleterious effect on osteogenesis and fusion. ${ }^{6} 71620$ 30-32 However, these studies lacked large cohorts of patients, statistical strength and discriminate usage of ketorolac. Additionally, many of their conclusions were based on poorly designed animal studies. ${ }^{1202330}$ More recent literature suggests that perhaps the adverse effects of NSAIDs on spinal fusions are likely type specific, dose and duration dependent. ${ }^{132122} 33-37$ Recent literature has demonstrated that ketorolac is a safe adjuvant for postoperative analgesia with no effect on fusion rates. ${ }^{6} 1620303238$ However, many of these are limited to retrospective studies or animal studies. To date, there has been no prospective randomised controlled trial to evaluate the effect of postoperative exposure to a minimum effective dose of ketorolac on fusion rates.

The growing opioid epidemic has caused nearly a quarter of million deaths in America over the past decade, ${ }^{39}$ and studies have shown the treatment of acute postoperative pain as the possible inciting event to long-term
- This study requires a large sample size. 
addiction. ${ }^{40}$ If our study demonstrates that ketorolac, in a minimally effective dose, can achieve comparable pain relief in a multimodal analgesia regimen without longterm adverse effects on spinal fusion, we can potentially contribute positively to the current opioid addiction epidemic. We hypothesise that low-dose ketorolac use in the early postoperative period provides adequate analgesia without long-term adverse effects on spinal fusion rates.

\section{STUDY GOALS AND OBJECTIVES}

Our goal is to demonstrate that ketorolac is a safe and effective adjuvant for postoperative analgesia without any adverse effect on fusion rates in adults.

\section{Primary objective}

To demonstrate that the use of ketorolac does not decrease thoracolumbar spinal fusion rates.

\section{Secondary objectives}

- To demonstrate that ketorolac decreases postoperative opioid use following thoracolumbar posterior spinal fusion in the first 48 hours.

- To demonstrate that ketorolac provides adequate pain relief when compared with the non-ketorolac group.

- To demonstrate that the use of ketorolac decreases the average length of stay following thoracolumbar spinal fusion.

- To determine any short-term in-hospital ketorolac-related complications.

\section{METHODS AND ANALYSIS}

This is a multihospital, prospective, double-blinded, randomised placebo-controlled trial in adults in accordance with Standard Protocol Items: Recommendations for Interventional Trials (SPIRIT) guidelines. This study will have two-arm parallel design without cross over and equal randomisation per arm.

Table 1 provides details of the inclusion, exclusion and withdrawal criteria.

Over a 3-year period, consecutive adult patients ages 18-80 who elect to undergo posterior thoracolumbar spinal fusion at two sites in secondary and tertiary care settings will be assessed for eligibility. Recruitment of participants is based on those adults who fulfil clinical criteria to undergo thoracolumbar spinal fusion as determined by the attending physicians. After satisfying inclusion/exclusion criteria, patients are consented and scheduled for surgery at Ascension Providence Hospital, Southfield or Novi Campus. On the day of surgery, patients are randomised with a centralised treatment allocation mechanism and block randomisation to assure the two arms achieve equal proportion of patients over time.

All patients, treatment providers, investigators and statisticians are blinded to the allocation. Blinding is achieved by allocation sequence being concealed to personnel involved in the enrolling, care and evaluation of the patient. The study coordinator will keep the randomisation schedule in a cloud-based, secure and encrypted database. Only the study coordinator who monitors the trial, the pharmacist who executes the allocation, the supervising investigator who is not involved in the

Table 1 Eligibility criteria

\section{Inclusion}

18 years of age or older

Elective posterior thoracolumbar fusion

Minimally invasive surgery

Three or less levels

Bone morphogenic protein use in interbody fusion

Consent to study participation

\section{Exclusion}

Patients with a history of drug-seeking behaviour or chemical addiction currently requiring treatment

Creatinine $>1.50 \mathrm{mg} / \mathrm{dL}$

History of coagulopathy

Active tobacco smoker or history in the past 6 weeks

Revision of fusion at operative level(s)

History of autoimmune/rheumatological condition

Oral systemic steroid use for 1 week in the last 1 month

Auto/worker's compensation

Trauma pathology at the operative levels

Infection at the operative levels

Tumour at operative level

Patients on chemotherapeutic agents in the last 6 months

Patients who have a history of allergy to ketorolac

History of liver impairment/failure

Uncontrolled cardiovascular disease

Criteria for discontinuing follow-up

Subject wishing to terminate participation in the study at any time throughout his/her participation 
Table 2 Standardised analgesic regimen

\begin{tabular}{|c|c|}
\hline Location & Medication \\
\hline Perioperative & $\begin{array}{l}\text { Induction: per anaesthesia protocol } \\
\text { Ketamine infusion } 10 \mu \mathrm{g} / \mathrm{kg} / \mathrm{min} \text { : initiated at induction, discontinued during closing } \\
\text { Fentanyl intravenous as needed (amount recorded) } \\
20 \mathrm{~mL} 1 \% \text { lidocaine } / 0.25 \% \text { bupivacaine with epinephrine injected locally }\end{array}$ \\
\hline $\begin{array}{l}\text { Postoperative (PO) - Post- } \\
\text { Anaesthesia Care Unit } \\
\text { (PACU) }\end{array}$ & $\begin{array}{l}\text { Intervention group: } \\
\text { Ketorolac } 15 \mathrm{mg}(15 \mathrm{mg} / \mathrm{mL}) \text { intravenous } \mathrm{Q} 6 \mathrm{H} \\
\text { Dilaudid intravenous } 0.5-2 \mathrm{mg}, 10 \mathrm{~min} \text { in between doses. Not to exceed } 2 \mathrm{mg} \\
\text { Control group: } \\
\text { Saline } 1 \mathrm{~mL} \text { intravenous } \mathrm{Q} 6 \mathrm{H} \\
\text { Dilaudid intravenous } 0.5-2 \mathrm{mg}, 10 \mathrm{~min} \text { in between doses. Not to exceed } 2 \mathrm{mg}\end{array}$ \\
\hline PO-floor & $\begin{array}{l}\text { Intervention group: } \\
\text { On arrival, ketorolac } 15 \mathrm{mg} \text { intravenous every } 6 \text { hours from the PACU dose for } 48 \text { hours } \\
\text { Total ketorolac will be }<110 \mathrm{mg} / \text { day for } 48 \text { hours } \\
\text { Dilaudid intravenous } 0.5-2 \mathrm{mg}, \mathrm{Q} 3 \mathrm{H} \text { PR }- \text { severe pain } \\
\text { Oxycodone/acetaminophen PO } 5 / 325 \text { two tab, Q4H as needed-moderate pain } \\
\text { Robaxin } 750 \mathrm{mg} \mathrm{PO}, \mathrm{Q} 6 \mathrm{H} \text { as needed } \\
\text { Return to home non-opioid medications } \\
\text { Control group:On arrival, normal saline } 1 \mathrm{~mL} \text { intravenous every } 6 \text { hours from the PACU dose for } \\
48 \text { hours } \\
\text { Dilaudid intravenous } 0.5-2 \mathrm{mg} \text { push, Q3H PRN-severe pain } \\
\text { Oxycodone/acetaminophen PO } 5 / 3252 \text { tab, Q4H as needed-moderate pain } \\
\text { Robaxin } 750 \text { mg PO, Q6H as needed } \\
\text { Convert all opioid doses to morphine equivalence } \\
\text { Return to home non-opioid medications }\end{array}$ \\
\hline
\end{tabular}

patients' care or enrolment will have access to the randomisation schedule. Pharmacy will prepare special syringes which will conceal the identity of the medications. Same volume of saline will be used as control.

Each patient receives standard general anaesthesia protocol. The patient will undergo minimally invasive thoracolumbar instrumented fusion according to the institutional standard of care. Postoperatively, each patient receives standardised analgesic regimen, summarised in Table 2, in addition to their treatment allocation. Each patient is followed according to the data collection schedule (table 3 ). While in the hospital, the patients are followed up on multiple times daily for any major adverse events (AEs), giving specific attention to gastrointestinal bleeding, postoperative wound or spinal haematoma, and acute kidney injury (AKI) as defined as an increase in $\mathrm{Cr}>50 \%$ from baseline. All AEs are reported to the principal investigator (PI) and subsequently to the institutional review board (IRB) within 24 hours of the AE. The intervention will be stopped if the patients experience the above AEs or if the patients refuse further participation in the study.

All patients enrolled have postoperative follow-up appointments scheduled for 6 months and 1 year with radiographic images specifically for the determination of primary outcome, in addition to routinely scheduled postoperative visits, determined by the primary surgeon. Each fusion level will be evaluated individually and as part of the complete fusion construct. Fusion will be determined by two blinded independent neuroradiologists using a combination of static and dynamic anterior-posterior (AP) and lateral X-rays (XR). If disagreement between radiologist occurs, a blinded surgeon not involved in the study will determine the presence or absence of fusion. While the use of XR is the standard of care to evaluate fusion in postfusion patients, the use of CT for the evaluation of fusion will be only performed in symptomatic patients. ${ }^{41}$ CT has the strongest correlation with the assessment of fusion status. ${ }^{42}$ However, given the size of the study and the burden of radiation exposure with CT, we have chosen to use XR as our method of evaluation. The 2014 American Association of Neurological Surgeons (AANS) guidelines state that a combination of static and lateral flexion/extension images is a valid and useful way of determining fusion in posterior lumbar fusions with instrumentation as supported by Brodsky et al, who determined the correlation of fusion rates with such images using surgical exploration. ${ }^{43}$ The diagnostic criteria are: halo or lucency around the hardware, absence of spinous process movement on flexion/ extension films and osseous bridging. Bridging trabeculae is referring to fusion across the disc space on lateral radiographs or posterolateral fusion on AP radiographs with bilateral and unilateral posterolateral continuous intertransverse bony bridging being considered fused at a single level (table 4$).{ }^{44}$ Those patients assessed at 1 year, who are determined to have non-union, will have additional follow-up established to further evaluate fusion status up to 2 years following their surgery date. 
Table 3 Study protocol timeline

\begin{tabular}{|c|c|c|c|c|c|c|c|c|}
\hline & Screening & DO (surgery) & D1 & D2 & D3 & D4 & 6 months & 12 months \\
\hline Eligibility & $x$ & & & & & & & \\
\hline Recruitment & $x$ & & & & & & & \\
\hline Consenting & $\mathrm{x}$ & & & & & & & \\
\hline Clinical examination & $\mathrm{x}$ & $\mathrm{x}$ & & & & & & \\
\hline Preoperative screening & & $\mathrm{x}$ & & & & & & \\
\hline Randomisation & & $x$ & & & & & & \\
\hline Toradol/control dose & & $x$ & $\mathrm{x}$ & $\mathrm{x}$ & & & & \\
\hline \multicolumn{9}{|l|}{ Adverse events } \\
\hline GI bleed & & $\mathrm{x}$ & $\mathrm{x}$ & $x$ & $x$ & $x$ & & \\
\hline $\begin{array}{l}\text { Postoperative superficial } \\
\text { haematoma }\end{array}$ & & $x$ & $x$ & $x$ & $x$ & $x$ & & \\
\hline Spinal epidural haematoma & & $x$ & $x$ & $x$ & $x$ & $\mathrm{x}$ & & \\
\hline Pseudarthrosis & & & & & & & $x$ & $\mathrm{x}$ \\
\hline \multicolumn{9}{|l|}{ Quality of life measures } \\
\hline SF-12 & $x$ & & & & & & $x$ & $x$ \\
\hline ODI & $x$ & & & & & & $\mathrm{x}$ & $x$ \\
\hline Visual Analogue Scale & $x$ & $x$ & $\mathrm{X}$ & $\mathrm{X}$ & $\mathrm{X}$ & $\mathrm{X}$ & $x$ & $x$ \\
\hline Radiographic imaging & & & & & & & $x$ & $\mathrm{x}$ \\
\hline
\end{tabular}

GI, gastro intestinal; ODI, Oswestry Disability Index.

Patient-reported outcomes are collected via the SF-12, Oswestry Disability Index and Visual Analogue Scale for the baseline and during postoperative intervals. Figure 1 outlines the study design and flow.

To demonstrate equivalency, a $95 \%$ power is used to minimise chances of false negatives. Baseline fusion rate at our institution with the use of bone morphogenic protein (BMP) is approximately $95 \%$. In order to detect a decreased fusion rate to $80 \%$ with $5 \%$ chance of making false-positive and false-negative conclusions, we estimate for the primary outcome a sample size of 300 patients per arm.

\section{Patient and public involvement}

At the time of enrolment, patients will be asked to participate as study advisers in our data monitoring and safety committee. There would be 2-4 patient advisers at any given time during the study period, each with a term of 1 year. These patient advisers will share their experience

\begin{tabular}{lll}
\hline Table 4 & Fusion criteria $^{45}$ & \\
\hline & $\begin{array}{l}\text { Formation of crossing } \\
\text { bony trabeculae }\end{array}$ & $\begin{array}{l}\text { Motion less than } 4^{\circ} \\
\text { between spinous } \\
\text { processes }\end{array}$ \\
$\begin{array}{l}\text { Solid union } \\
\text { union }\end{array}$ & $\begin{array}{l}\text { Questionable trabecular } \\
\text { crossing }\end{array}$ & $\begin{array}{l}\text { Motion less than } 4^{\circ} \\
\text { between spinous } \\
\text { processes }\end{array}$ \\
Non-union & $\begin{array}{l}\text { Bilateral presence } \\
\text { of visible gap/graft } \\
\text { collapse }\end{array}$ & $\begin{array}{l}\text { Motion greater than } \\
4^{\circ} \text { between spinous } \\
\text { processes }\end{array}$ \\
\hline
\end{tabular}

regarding the recruitment process, surgery, postoperative care and pain control in order to help ensure patient safety and satisfaction throughout the study.

\section{DISCUSSION}

Ketorolac has been shown to provide quality postoperative pain control, decrease opioid requirement with minimal side effects following spinal surgery. ${ }^{7} 174143$ However, the literature with regard to its use in spinal fusions is highly variable in both its effectiveness and complications such as pseudarthrosis. ${ }^{671617203044}$ Recent literature with meta-analyses and systematic reviews postulates that perhaps short-term low-dose ketorolac does not affect fusion rates. ${ }^{17}$ Additionally, they recognise a need for large randomised controlled trials. ${ }^{17}$

In this trial, we hope to demonstrate that a minimally effect dose of ketorolac will not adversely impact fusion rates in thoracolumbar fusion. We also seek to show that ketorolac has an equivocal analgesic capacity for controlling acute postoperative pain when compared with opioids alone.

\section{Trial status}

At the time of manuscript submission, the trial is ongoing.

\section{Safety considerations}

All study-related AEs are recorded and reported immediately to the PI. The PI will then submit an AE log to the IRB within 24 hours of the event. All AE will be logged in an adverse outcome reporting log as needed. The institutional 


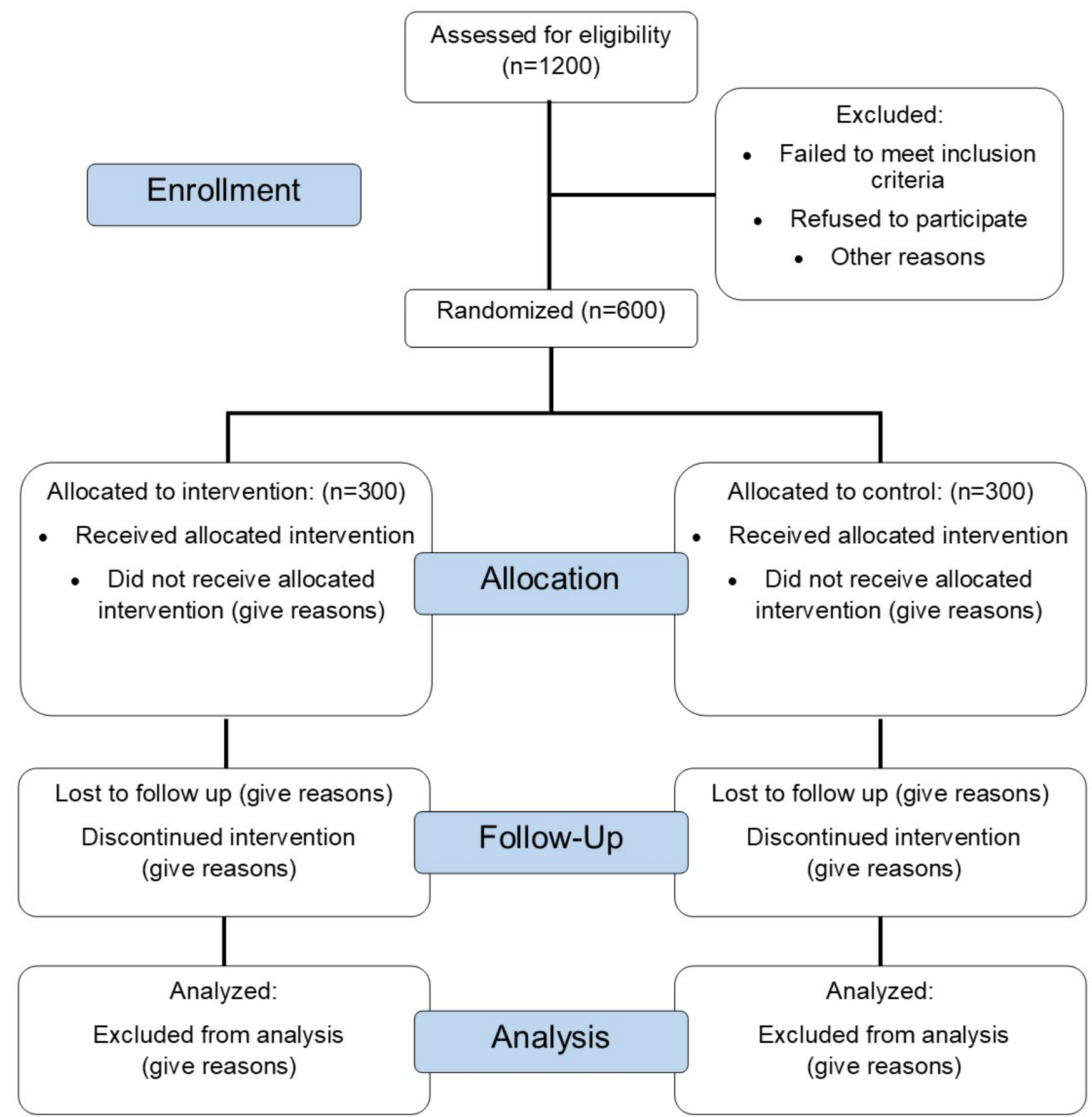

Figure 1 Study design Consolidated Standards Of Reporting Trials (CONSORT) flow diagram.

data safety monitoring board (DSMB) will be responsible for monitoring the clinical and surgical safety of the study and review AEs reported to the IRB to determine risk and benefits. Any AE related to the study medication represents a circumstance under which unblinding is permissible in order to ensure the safety of the participant. At that time, the intervention will be stopped, and any clinical intervention required at the discretion of the attending surgeon will ensue and documented and presented to the IRB and DSMB. Members of the DSMB will be surgeons and related experts who will meet to review the results and any AEs biannually to evaluate study safety.

\section{Follow-up}

Postoperatively, patients are followed up every 4 hours during which AEs will be prospectively collected using a standardised specific adverse outcome clinical report form (CRF). Study participants will also be instructed to contact the PI in case of suspected AEs related to study medication in order to schedule additional visits for 
evaluation. Study participants that have been determined to have pseudoarthrosis after the completion of data collection will have further follow-up instruction by their primary surgeon.

\section{Data management and statistical analysis}

During the first 2 weeks of the trial, the PI, CRC will observe the various steps of the intervention and data collection to ensure proper execution. The progress of data entry, follow-up and recruitment is monitored regularly by different logs which are reviewed by the CRC. The CRF will be entered into the database within 24 hours of the patient's discharge and the database will be maintained to within 1 week of the data collection. CRC will evaluate the capture rate for the postoperative interviews/radiographic examination at 6 months and 1 year. An interim analysis will be conducted after 100 patients have been enrolled and completed study procedures.

Primary outcome, fusion, will be evaluated by the Suk criteria ${ }^{45}$ and analysed by $\chi^{2}$ test. Additionally, the comparability of the two groups baseline characteristics is evaluated by univariate analyses. These univariate analyses are exploratory. If there are any confounders imbalance between the two groups, ordinal regression will be performed using our primary fusion outcome as the dependent variable with patient baseline characteristics as the independent variables. The $\mathrm{p}$ value will be adjusted using Bonferroni correction. Imbalanced confounders will also be stratified for further subgroup analysis. Our secondary outcomes will be assessed using multivariate analysis with rank sum, t-test, $\chi^{2}$ test comparing the following demographics between study arms: age, sex, BMI, diabetes mellites, specific lumbar level, number of operative lumbar levels, total dose of fentanyl during surgery, duration of surgery, estimated blood loss, interval between surgery and fusion evaluation, BMP dose, types of non-opioid drug used and amount of opioids taken preoperatively.

Descriptive statistics will be used in each arm for proportion who did not receive allocated intervention, lost to follow-up, excluded from analysis and ketorolac-related complications. Intention to treat, per protocol and sensitivity analyses will be performed.

\section{Quality assurance}

Standardised medication orders will conceal the treatment allocation. The study coordinator will be responsible for managing the quality of patient data recorded in the study. All participating research staff will be trained and given written copies of a standard operating procedure to ensure consistency during recruitment and consent. The study coordinator along with the PI will check weekly the content of the forms and database to ensure accurate and timely entry. The recorded data will be entered into a cloud-based, secure and encrypted database by the research staff. Access to the database will be restricted. Data validation tool has been embedded in the database.
Data entered will undergo monthly verification with the source document.

\section{Expected outcome of the study}

This study is intended to demonstrate that low-dose ketorolac $(<110 \mathrm{mg} /$ day $)$ use in the early postoperative period (within 48 hours) safely provides adequate analgesia without long-term AEs on spinal fusion rates when compared with placebo. We expect to identify any possible immediate AEs such as, but not limited to, gastrointestinal bleeding, superficial or epidural haematoma, and/or AKI. Additionally, we aim to identify a decrease in postoperative opioid use demonstrated by a decrease in morphine equivalence while showing equivalent postoperative pain control. Moreover, length of stay is hypothesised to be lower among those who received ketorolac compared with placebo.

\section{Duration of the project}

With our 2016 institutional volume for lumbar surgeries at or near 900 procedures, and assuming $50 \%$ of eligible patients agree to participate, we anticipate roughly $2-3$ years to enrol 500-600 patients.

\section{Project management}

Neurosurgeons and orthopaedic spine surgeons will counsel and recruit subjects according to their indications to undergo posterior thoracolumbar spinal fusion. The trained research staff will check for eligibility using inclusion and exclusion criteria listed in table 1 . The research staff will also explain the study principles, including the detailed experimental postoperative protocol, investigational treatment, potential risks and benefits. Subsequent detailed written consent will be obtained by the research staff and placed in a cloud-based, secure, and encrypted database. The designated lead pharmacists will execute the randomised allocation assignment according to the block randomisation schedule to maintain masking of allocation. The head of neuroanaesthesia will be responsible for standardisation and monitoring of anaesthesia administered to study participants. The PI and support staff will record all intraoperative and postoperative data including study-related AEs. The study coordinator will ensure and maintain follow-up visits for postoperative radiographs. The neuroradiologists will evaluate and determine fusion in 6 months and 1-year follow-up X-ray as previously described in table 4 . The clinical research methodologist will function as CRC, supervise the overall execution of the study and participate in the writing of the protocol and manuscript.

\section{Ethics and dissemination}

The study will be conducted according to the Helsinki Declaration, ${ }^{46}$ the NIH human subjects guidelines and the International Conference on Harmonisation E6 Guideline for Good Clinical Practice. ${ }^{47}$ This protocol is written following the SPIRIT 2013 guidelines and was approved by the hospital IRB. The results of this study will be submitted for publication in peer-reviewed 
journals and the key findings will be presented at national conferences.

Contributors CFC, EL, DT, MB, PK, CH, PB, BR and TMS contributed substantially to the conception and design of this trial including organisation and execution over two hospital campuses. DS contributed to the design and execution of the study drug protocol including randomisation, blinding and placebo. DL contributed to the design and execution of the intraoperative standardised protocol in collaboration with pharmacy staff over two hospital campuses and ensuring accurate protocol adherence during surgery and in recovery unit. $A D, M L$ and $D S$ contributed substantially to the acquisition of data, ensuring accurate and standard operating procedures, and maintaining quality assurance among study participants and their subsequent care over two hospital campuses. CFC, EL, DT, MB, ML, DS, PK, CH, PB $B R$ and TMS contributed to the drafting of the original manuscript, participated in critically revising the manuscript and agree to be accountable for all aspects of the work.

Funding This trial is supported by Ascension Providence Hospital Research Department.

Competing interests None declared.

Patient consent for publication Not required.

Ethics approval The protocol was approved by the Ascension Providence Hospital Institutional Review Board.

Provenance and peer review Not commissioned; externally peer reviewed.

Open access This is an open access article distributed in accordance with the Creative Commons Attribution Non Commercial (CC BY-NC 4.0) license, which permits others to distribute, remix, adapt, build upon this work non-commercially, and license their derivative works on different terms, provided the original work is properly cited, appropriate credit is given, any changes made indicated, and the use is non-commercial. See: http://creativecommons.org/licenses/by-nc/4.0/.

\section{REFERENCES}

1. Li Q, Zhang Z, Cai Z. High-dose ketorolac affects adult spinal fusion: a meta-analysis of the effect of perioperative nonsteroidal antiinflammatory drugs on spinal fusion. Spine 2011;36:E461-8.

2. Kinsella J, Moffat AC, Patrick JA, et al. Ketorolac trometamol for postoperative analgesia after orthopaedic surgery. $\mathrm{Br} J$ Anaesth 1992;69:19-22.

3. Reuben SS, Connelly NR, Steinberg R. Ketorolac as an adjunct to patient-controlled morphine in postoperative spine surgery patients. Reg Anesth 1997;22:343-6.

4. Hernández-Palazón J, Tortosa JA, Martínez-Lage JF, et al. Intravenous administration of propacetamol reduces morphine consumption after spinal fusion surgery. Anesth Analg 2001;92:1473-6.

5. Jahr JS, Montalvo HM, Holton R, et al. Does ketorolac tromethamine, a new analgesic, decrease postoperative recovery time, narcotic requirements, nausea and/or vomiting, and unscheduled hospital admissions: a retrospective analysis. Acta Anaesthesiol Belg 1993;44:141-7.

6. Park SY, Moon SH, Park MS, et al. The effects of ketorolac injected via patient controlled analgesia postoperatively on spinal fusion. Yonsei Med J 2005;46:245-51.

7. Reuben SS, Connelly NR, Lurie S, et al. Dose-response of ketorolac as an adjunct to patient-controlled analgesia morphine in patients after spinal fusion surgery. Anesth Analg 1998;87:98-102.

8. Engesaeter LB, Sudmann B, Sudmann E. Fracture healing in rats inhibited by locally administered indomethacin. Acta Orthop Scand 1992;63:330-3.

9. Elmstedt E, Lindholm TS, Nilsson OS, et al. Effect of ibuprofen on heterotopic ossification after hip replacement. Acta Orthop Scand 1985;56:25-7.

10. Gerstenfeld LC, Al-Ghawas M, Alkhiary YM, et al. Selective and nonselective cyclooxygenase-2 inhibitors and experimental fracturehealing. Reversibility of effects after short-term treatment. J Bone Joint Surg Am 2007;89:114-25.

11. Gerstenfeld LC, Thiede M, Seibert K, et al. Differential inhibition of fracture healing by non-selective and cyclooxygenase-2 selective non-steroidal anti-inflammatory drugs. J Orthop Res 2003;21:670-5.

12. Brown KM, Saunders MM, Kirsch T, et al. Effect of COX-2-specific inhibition on fracture-healing in the rat femur. J Bone Joint Surg Am 2004;86-A:116-23.
13. Simon AM, O'Connor JP. Dose and time-dependent effects of cyclooxygenase-2 inhibition on fracture-healing. J Bone Joint Surg Am 2007;89:500-11.

14. Allen HL, Wase A, Bear WT. Indomethacin and aspirin: effect of nonsteroidal anti-inflammatory agents on the rate of fracture repair in the rat. Acta Orthop Scand 1980;51:595-600.

15. Dimar JR, Ante WA, Zhang YP, et al. The effects of nonsteroidal anti-inflammatory drugs on posterior spinal fusions in the rat. Spine 1996;21:1870-6.

16. Glassman SD, Rose SM, Dimar JR, et al. The effect of postoperative nonsteroidal anti-inflammatory drug administration on spinal fusion. Spine 1998;23:834-8.

17. Li J, Ajiboye RM, Orden MH, et al. The Effect of ketorolac on thoracolumbar posterolateral fusion: a systematic review and metaanalysis. Clin Spine Surg 2018;31:65-72.

18. Long J, Lewis S, Kuklo T, et al. The effect of cyclooxygenase-2 inhibitors on spinal fusion. J Bone Joint Surg Am 2002;84A:1763-8.

19. Martin GJ, Boden SD, Titus L. Recombinant human bone morphogenetic protein-2 overcomes the inhibitory effect of ketorolac, a nonsteroidal anti-inflammatory drug (NSAID), on posterolateral lumbar intertransverse process spine fusion. Spine 1999;24:2188-93. Discussion 2193-2194.

20. Pradhan BB, Tatsumi RL, Gallina J, et al. Ketorolac and spinal fusion: does the perioperative use of ketorolac really inhibit spinal fusion? Spine 2008;33:2079-82.

21. Reuben SS, Ablett D, Kaye R. High dose nonsteroidal antiinflammatory drugs compromise spinal fusion. Can $J$ Anaesth 2005;52:506-12.

22. Riew KD, Long J, Rhee J, et al. Time-dependent inhibitory effects of indomethacin on spinal fusion. J Bone Joint Surg Am 2003;85A:632-4.

23. Urrutia J, Mardones R, Quezada F. The effect of ketoprophen on lumbar spinal fusion healing in a rabbit model. Laboratory investigation. J Neurosurg Spine 2007;7:631-6.

24. Patel TC, Erulkar JS, Grauer JN, et al. Osteogenic protein-1 overcomes the inhibitory effect of nicotine on posterolateral lumbar fusion. Spine 2001;26:1656-61.

25. Blumenthal SL, Baker J, Dossett A, et al. The role of anterior lumbar fusion for internal disc disruption. Spine 1988;13:566-9.

26. Brown CW, Orme TJ, Richardson HD. The rate of pseudarthrosis (surgical nonunion) in patients who are smokers and patients who are nonsmokers: a comparison study. Spine 1986;11:942-3.

27. Minamide A, Kawakami M, Hashizume H, et al. Evaluation of carriers of bone morphogenetic protein for spinal fusion. Spine 2001;26:933-9.

28. Bydon M, De la Garza-Ramos R, Abt NB, et al. Impact of smoking on complication and pseudarthrosis rates after single- and 2-level posterolateral fusion of the lumbar spine. Spine 2014;39:1765-70.

29. Jiménez-Avila JM, García-Valencia J, Bitar-Alatorre WE. [Risk factors affecting fusion in the treatment of lumbar spine instability]. Acta Ortop Mex 2011;25:156-60.

30. Sucato DJ, Lovejoy JF, Agrawal S, et al. Postoperative ketorolac does not predispose to pseudoarthrosis following posterior spinal fusion and instrumentation for adolescent idiopathic scoliosis. Spine 2008;33:1119-24.

31. Dumont AS, Verma S, Dumont RJ, et al. Nonsteroidal antiinflammatory drugs and bone metabolism in spinal fusion surgery: a pharmacological quandary. J Pharmacol Toxicol Methods 2000:43:31-9.

32. Vitale MG, Choe JC, Hwang MW, et al. Use of ketorolac tromethamine in children undergoing scoliosis surgery. an analysis of complications. Spine J 2003;3:55-62.

33. Simon AM, Manigrasso MB, O'Connor JP. Cyclo-oxygenase 2 function is essential for bone fracture healing. $J$ Bone Miner Res 2002;17:963-76.

34. Lumawig JM, Yamazaki A, Watanabe K. Dose-dependent inhibition of diclofenac sodium on posterior lumbar interbody fusion rates. Spine J 2009;9:343-9.

35. Ho ML, Chang JK, Wang GJ. Effects of ketorolac on bone repair: a radiographic study in modeled demineralized bone matrix grafted rabbits. Pharmacology 1998;57:148-59.

36. $\mathrm{MI} \mathrm{H}$, Chang JK, Wang GJ. Antiinflammatory drug effects on bone repair and remodeling in rabbits. Clin Orthop 1995:270-8.

37. Bergenstock M, Min W, Simon AM, et al. A comparison between the effects of acetaminophen and celecoxib on bone fracture healing in rats. J Orthop Trauma 2005;19:717-23.

38. Donohue D, Sanders D, Serrano-Riera R, et al. Ketorolac administered in the recovery room for acute pain management does not affect healing rates of femoral and tibial fractures. J Orthop Trauma 2016;30:479-82. 
39. Gellad WF, Good CB, Shulkin DJ. Addressing the opioid epidemic in the united states: lessons from the department of veterans affairs. JAMA Intern Med 2017;177:611-612.

40. Callinan CE, Neuman MD, Lacy KE, et al. The initiation of chronic opioids: a survey of chronic pain patients. J Pain 2017;18:360-5.

41. Choudhri TF, Mummaneni PV, Dhall SS, et al. Guideline update for the performance of fusion procedures for degenerative disease of the lumbar spine. Part 4: radiographic assessment of fusion status. $J$ Neurosurg Spine 2014;21:23-30.

42. Chun DS, Baker KC, Hsu WK. Lumbar pseudarthrosis: a review of current diagnosis and treatment. Neurosurg Focus 2015;39:E10.

43. Brodsky AE, Kovalsky ES, Khalil MA. Correlation of radiologic assessment of lumbar spine fusions with surgical exploration. Spine 1991;16:S261-5.

44. Christensen FB, Laursen M, Gelineck J, et al. Interobserver and intraobserver agreement of radiograph interpretation with and without pedicle screw implants: the need for a detailed classification system in posterolateral spinal fusion. Spine 2001;26:538-43. Discussion 543-544.

45. Suk SI, Lee CK, Kim WJ, et al. Adding posterior lumbar interbody fusion to pedicle screw fixation and posterolateral fusion after decompression in spondylolytic spondylolisthesis. Spine 1997;22:210-9.

46. Puri KS, Suresh KR, Gogtay NJ, et al. Declaration of Helsinki, 2008: implications for stakeholders in research. J Postgrad Med 2009;55:131-4.

47. Abraham J. International Conference On Harmonisation Of Technical Requirements For Registration Of Pharmaceuticals For Human Use. In: Brouder A, Tietje C, eds. Handbook of transnational economic governance regimes. Brill, 2009:1041-54. 